\title{
How Volatile is ENSO for Global Greenhouse \\ Gas Emissions and the Global Economy?
}

\author{
Lan-Fen Chu \\ National Science and Technology Center for Disaster \\ Taiwan
}

\begin{abstract}
Michael McAleer*
Econometric Institute

Erasmus School of Economics

Erasmus University Rotterdam

and

Institute of Economic Research

Kyoto University

and

Department of Quantitative Economics

Complutense University of Madrid

\author{
Chi-Chung Chen \\ Department of Applied Economics \\ National Chung Hsing University \\ Taiwan.
}

Revised: September 2012
* The second author is grateful for the financial support of the Australian Research Council, National Science Council, Taiwan, and the Japan Society for the Promotion of Science.




\begin{abstract}
This paper analyzes two indexes in order to capture the volatility inherent in El Niños Southern Oscillations (ENSO), develops the relationship between the strength of ENSO and greenhouse gas emissions, which increase as the economy grows, with carbon dioxide being the major greenhouse gas, and examines how these gases affect the frequency and strength of El Niño on the global economy. The empirical results show that both the ARMA(1,1)-GARCH(1,1) and ARMA(3,2)-GJR(1,1) models are suitable for modelling ENSO volatility accurately, and that 1998 is a turning point, which indicates that the ENSO strength has increased since 1998. Moreover, the increasing ENSO strength is due to the increase in greenhouse gas emissions. The ENSO strengths for Sea Surface Temperature (SST) are predicted for the year 2030 to increase from $29.62 \%$ to $81.5 \%$ if global $\mathrm{CO}_{2}$ emissions increase by $40 \%$ to $110 \%$, respectively. This indicates that we will be faced with even stronger El Nino or La Nina effects in the future if global greenhouse gas emissions continue to increase unabated.
\end{abstract}

Keywords: El Niños Southern Oscillations (ENSO), Greenhouse Gas Emissions, Global Economy, Southern Oscillation Index (SOI), Sea Surface Temperature (SST), Volatility. 


\section{Introduction}

The El Niños Southern Oscillations (ENSO) is a periodical phenomenon of climatic inter-annual variability which has been found to be associated with regional variations in climate throughout the world, and has important implications for global greenhouse gas emissions. ENSO includes three phases, El Niños, La Niña, and Neutral, which could be defined through either the Southern Oscillation Index (SOI) or the Sea Surface Temperature (SST) Index. These ENSO phases have been found to have significant impacts on global/local agriculture, water, and fishery sectors during alternative ENSO phases, strength, and frequency. For instance, the relationship between ENSO and precipitation, stream flow, floods and droughts has been investigated and analyzed (McBride and Nicholls, 1983; Ropelewski and Halpert, 1989; Dracup and Kahya, 1994; Moss et al., 1994; Piechota and Dracup, 1996) in recent years, reflecting the importance of this topical issue.

There is an extensive literature devoted to estimating the economic impacts of ENSO on the agricultural and water sectors, such as Handler (1983), Adams et al. (1995), Adams et al. (1999), Solow et al. (1998), Chen and McCarl (2000), Chen et al. (2001), Chen, McCarl and Hill (2002), Dilley (1997), Naylor et al. (2001), and Brunner (2002). These studies examine not only the importance of ENSO information on the agricultural economy, but are also linked to fluctuations in ENSO and the macro economy (Debelle and Stevens, 1995; Brian et. al., 2008).

During the past decade, some attention has been transferred to issues of food safety and public health. Some notable examples, including Davis (2001), have been devoted to the relationship between ENSO events and famine, while Kovats et al. (2003) investigated the variation in cholera risk in Bangladesh, and malaria epidemics in South Asia and South America. Other investigations suggest that hurricane losses are much greater during a La Niña year in the USA (Pielke and Landsea, 1999), while 
Chen et al. (2005) used ENSO frequency data to investigate Edwards Aquifer water and agricultural management on the phases of ENSO.

The above examples suggest that the damage of ENSO events could be mitigated if ENSO information could be forecast accurately. This implies that ENSO information, including the strength and frequency of ENSO phases, needs to be measures and collated accurately. However, ENSO strength and frequency have shifted (Timmermann et al., 1999), and greenhouse gas emissions may be one such cause. In other words, ENSO volatility varies over time.

The first purpose of this paper is to investigate ENSO volatility using generalized autoregressive conditional heteroskedasticity (GARCH) time series models. Such empirical findings will provide important information regarding ENSO volatility. The second purpose of the paper is to link the relationship between ENSO strength and greenhouse gas emissions, and to predict the future ENSO strength based on alternative climate change scenarios from IPCC (2007). Such empirical findings will provide critical information regarding the impact of the possibly stronger El Nino and La Nina occurrences in the near future on greenhouse gas emissions.

The remainder of the paper is organized as follows. Section 2 presents the empirical models, while Section 3 discusses the data and descriptive statistics. Section 4 analyzes the empirical results. The linkages between the ENSO strength and greenhouse gas emissions are estimated in Section 5. Some concluding remarks are given in the final section.

\section{The Models}

Modeling ENSO phases using ARMA and/or ARCH models has been considered by Chu and Katz (1985), Trenberth and Hoar (1996), and Ahn and Kim (2005). Chu and Katz (1985) found that monthly SOI can be modelled adequately by AR(3) 
processes, while Trenberth and Hoar (1996) found that an ARMA(3,1) model can be fitted for SST by using maximum likelihood and Akaike's Information Criterion (AIC). Ahn and Kim (2005) found that ARCH is a more suitable model for the SOI

series. Each of these studies paid attention to either the SOI or SST index, but not both, which may misrepresent ENSO characteristics as both of these indexes can be used to define ENSO phases. On the other hand, although empirical research has used time series models, including ARMA, ARCH, and $\mathrm{GARCH}$, to analyze the ENSO index, the model adequacy of ENSO volatility has not yet been examined.

In order to answer these two questions, the generalized autoregressive conditional heteroskedasticity $(\mathrm{GARCH})$ model will be applied to the SOI and SST indexes. Bai and Perron's $(1998,2003)$ approach will be adopted in order to capture the structural break point of the ENSO series, which could identify alternative time periods for purposes of estimating ENSO volatility.

\subsection{Conditional Mean and Conditional Volatility Models}

Based on the pioneering work of Engle (1982) in capturing time-varying volatility, the autoregressive conditional heteroskedasticity (ARCH) model, and subsequent developments forming the generalized ARCH (GARCH) model of Bollerslev (1986), has been used to capture volatility. The GARCH model is most wildly used for symmetric shocks, but when asymmetric shocks exist, the GJR model of Glosten et al. (1992), or the EGARCH model of Nelson (1991), are also popular. Some further theoretical developments have been suggested by Wong and Li (1997), and Ling and McAleer (2002a, 2002b, 2003a, 2003b) and McAleer (2005). The volatility models to be used in this section have been discussed by, among others, McAleer et al. (2007) and Divino and McAleer (2009).

In this paper, we consider the stationary $\operatorname{AR}(1)-\operatorname{GARCH}(1,1)$ or 
ARMA(p,q)-GARCH(1,1) models for the SOI and SST series data, namely $y_{t}$ :

$$
\begin{aligned}
& y_{t}=\phi_{1}+\phi_{2} y_{t-1}+\varepsilon_{t}, \quad \text { for } t=1, \ldots, n, \\
& y_{t}=\operatorname{ARMA}(p, q)+\varepsilon_{t}
\end{aligned}
$$

where $\varepsilon_{t}$ is unconditional shocks (or movements in the indices of SOI or SST) are given by:

$$
\begin{aligned}
& \varepsilon_{t}=\eta_{t} \sqrt{h_{t}}, \eta_{t} \sim \operatorname{iid}(0,1), \\
& h_{t}=\omega+\alpha \varepsilon_{t-1}^{2}+\beta h_{t-1},
\end{aligned}
$$

and $\omega \geq 0, \alpha \geq 0, \beta \geq 0$ are sufficient conditions to ensure that the conditional variance $h_{t} \geq 0$. Ling and McAleer (2003b) indicated equation (2) could be modified to incorporate a non-stationary $\operatorname{ARMA}(\mathrm{p}, \mathrm{q})$ conditional mean and a stationary $\operatorname{GARCH}(\mathrm{r}, \mathrm{s})$ conditional variance. In (2), the $\alpha$ (or ARCH) effect indicates the short run persistence of shocks, while the $\beta$ (or GARCH) effect indicates the contribution of shocks to long run persistence (namely, $\alpha+\beta$ ).

As the GARCH process in equation (2) is a function of the unconditional shocks, the moments of $\varepsilon_{t}$ need to be investigated. Based on the studies of Ling and Li (1997) and Ling and McAleer (2002a, 2002b) (see also Bollerslev (1986) and Nelson (1990), the necessary and sufficient condition for the existence of the second moment of $\varepsilon_{t}$ for $\operatorname{GARCH}(1,1)$ is $\alpha+\beta<1$ and, under normality, the necessary and sufficient condition for the existence of the fourth moment is $(\alpha+\beta)^{2}+2 \alpha^{2}<1$.

The effects of a positive shock on the conditional variance, $h_{t}$, is assumed to be the same as a negative shock of a similar magnitude in the symmetric GARCH model. In order to accommodate asymmetric behavior, Glosten et al. (1992) proposed the GJR model, for which GJR(1,1) is defined as follows:

$$
h_{t}=\omega+\left(\alpha+\gamma I\left(\eta_{t-1}\right)\right) \varepsilon_{t-1}^{2}+\beta h_{t-1}
$$

where $\omega>0, \alpha \geq 0, \alpha+\gamma \geq 0, \beta \geq 0$ are sufficient conditions for $h_{t}>0$ and 
$I\left(\eta_{t}\right)$ is an indicator variable defined by

$$
I\left(\eta_{t}\right)= \begin{cases}1 & \varepsilon_{t}<0 . \\ 0 & \varepsilon_{t} \geq 0\end{cases}
$$

as $\eta_{t}$ has the same sign as $\varepsilon_{t}$. The indicator variable differentiates between positive and negative shocks, so that asymmetric effects in the data are captured by the coefficient $\gamma$, with the expectation that $\gamma \geq 0$. The asymmetric effect, $\gamma$, measures the contribution of shocks to both short run persistence, $\alpha+\gamma / 2$, and to long run persistence, $\alpha+\beta+\gamma / 2$. As the ARCH effect, $\alpha$, must be negative for leverage, in which positive shocks decrease volatility while negative shocks of equal magnitude increase volatility, leverage is not possible for the GJR model.

Ling and McAleer (2002b) derived the unique strictly stationary and ergodic solution of a family of GARCH processes, which includes GJR $(1,1)$ as a special case, a simple sufficient condition for the existence of the solution, and the necessary and sufficient condition for the existence of the moments. For the special case of $\operatorname{GJR}(1,1)$, Ling and McAleer (2002b) showed that the regularity condition for the existence of the second moment under symmetry of $\eta_{t}$ is

$$
\alpha+\beta+\frac{1}{2}<1
$$

and the condition for the existence of the fourth moment under normality of $\eta_{t}$ is

$$
\beta^{2}+2 \alpha \beta+3 \alpha+\beta \gamma+3 \alpha \beta+\frac{3}{2} \gamma^{2}<1
$$

while McAleer et al. (2007) showed that the weaker log-moment condition for GJR(1,1) was given by

$$
E\left(\ln \left[\left(\alpha+\gamma I\left(\eta_{t}\right)\right) \eta_{t}^{2}+\beta\right]\right)<0
$$

which involves the expectation of a function of a random variable and unknown parameters.

An alternative model to capture asymmetric behavior in the conditional variance 
is the Exponential GARCH (EGARCH(1,1)) model of Nelson (1991), namely:

$$
\log h_{t}=\omega+\alpha\left|\eta_{t-1}\right|+\gamma \eta_{t-1}+\beta \log h_{t-1},|\beta|<1
$$

where the parameters $\alpha, \beta$ and $\gamma$ have different interpretations from those in the GARCH $(1,1)$ and GJR $(1,1)$ models. Leverage is possible in the EGARCH model as it depends on the respective magnitudes of $\alpha$ and $\gamma$.

As noted in McAleer et al. (2007), there are some important differences between EGARCH and the previous two models, as follows: (i) EGARCH is a model of the logarithm of the conditional variance, which implies that no restrictions on the parameters are required to ensure $h_{t}>0$; (ii) Nelson (1991) showed that $|\beta|<1$ ensures stationarity and ergodicity for $\operatorname{EGARCH}(1,1)$; (iii) Shephard (1996) observed that $|\beta|<1$ is likely to be a sufficient condition for consistency of QMLE for $\operatorname{EGARCH}(1,1)$; (iv) as the conditional (or standardized) shocks appear in equation (3), $|\beta|<1$ would seem to be a sufficient condition for the existence of moments; and (v) in addition to being a sufficient condition for consistency, $|\beta|<1$ is also likely to be sufficient for asymptotic normality of the QMLE of EGARCH(1,1).

Furthermore, EGARCH captures asymmetries differently from GJR. The parameters $\alpha$ and $\gamma$ in $\operatorname{EGARCH}(1,1)$ represent the magnitude (or size) and sign effects of the conditional (or standardized) shocks, respectively, on the conditional variance, whereas $\alpha$ and $\alpha+\gamma$ represent the effects of positive and negative shocks, respectively, of a similar magnitude on the conditional variance in $\operatorname{GJR}(1,1)$.

\subsection{Modelling Structural Breaks}

The strength, duration, and frequency of ENSO phases have increased during the last two decades (Trenberth and Hoar, 1996; Hall et al., 2001), which suggests that 
there may have been structural breaks in ENSO. Much research related to structural breakpoints has been undertaken by Quandt (1958), Chow (1960) Andrews (1993), and Hansen (2001), which need a priori break points before implementation. However, the approach by Bai and Perron $(1998,2003)$ (hereafter BP) does not need the a priori assumption of break points.

The BP method provides a comprehensive treatment based on the following steps. First, consider the $\operatorname{supF}(\mathrm{i} \mid 0)$ type tests (that is, a series of Wald tests) of a nonstructural break $(\mathrm{i}=0)$ against $\mathrm{i}=\mathrm{k}$ breaks. This test requires a pre-specification of a number of breaks for inference, and then to use the double maximum test $\left(\mathrm{UD}_{\max }\right.$ and $\mathrm{WD}_{\max }$ ) of the null hypothesis of no structural break against an unknown number of breaks. These tests are used to determine if there is at least one structural break, while the structural break is determined endogenously. In this paper, the maximum number of breaks (i) is chosen to be 5 , which is based on the Liu, Wu and Zidek (LWZ) criterion.

Following the estimation approach of Bai and Perron $(1998,2003)$, if these tests show evidence of at least one structural break, then the number of breaks can be determined by using the $\operatorname{supF}(i+1 \mid i)$ test, which performs parameter constancy tests for every subsample obtained by cutting off at the estimated breaks, and then by adding a break to a sub-sample associated with a rejection. This process is repeated by increasing $\mathrm{i}$ sequentially until the test fails to reject the null hypothesis of no additional structural breaks.

\section{Data and Descriptive Statistics}

The most common indexes to describe ENSO phases are referred to as the Southern Oscillation Index (SOI) and Sea Surface Temperature (SST) Index, which are monthly data sets. SOI is calculated from the monthly inverse variations in the 
air pressure difference between Tahiti $\left(17.5^{\circ} \mathrm{S}, 149.6^{\circ} \mathrm{W}\right)$ in the South Pacific Ocean and Darwin $\left(12.4^{\circ} \mathrm{S}, 130.9^{\circ} \mathrm{W}\right)$ in northern Australia. Positive values of the SOI are popularly known as a La Niña phase, while negative values are called El Niño. SST is the water temperature close to the surface in the Equatorial Pacific Ocean (that is, 4 for the region $5^{\circ} \mathrm{N}-5^{\circ} \mathrm{S}, 120^{\circ}-170^{\circ} \mathrm{W}$ ). If the period during 5-month rolling means of the monthly SST anomalies in the above-mentioned area are $+5^{0} \mathrm{C}$ or more for at least six consecutive months, this is called a Niño year (Trenberth, 1997).

Figure 1 plots the time series data set for SOI and SST. These two graphs indicate periods of high volatility followed by others of relatively low volatility, which implies that using homoskedastic residuals to model volatility behaviour is inappropriate. Furthermore, we also find that volatility in the most recent periods is higher than in the earlier periods, as shown in the left graph of Figure 1, which implies that ENSO volatility has been increasing.

The data sets for the SOI and SST observations are collected from the Climate Prediction Center from January 1933 to July 2007 and January 1950 to April 2007, respectively. Table 1 displays the descriptive statistics for the SOI and SST series. The SOI series has a larger variance than the SST series. The Ljung-Box Q-statistics for SOI and SST are given as $\mathrm{Q}(12)=1290.20$ and $\mathrm{Q}(12)=2149.50$, respectively, which correspond to p-values of the two test statistics of less than $5 \%$, thereby suggesting that SOI and SST are correlated. In order to test normality, the JB Lagrange multiplier test statistic is used. Table 1 shows that SOI and SST are not normally distributed, as the p-values of the JB statistics are less than 5\%.

Before establishing the volatility model for the SOI and SSI series, unit roots tests have to be implemented to ensure the data of the SOI and SSI series are stationary. The most common unit root tests are those of Dickey and Fuller (1979, 1981), who developed tests of the null hypothesis of a unit root against the alternative 
of stationarity. In this paper, the augmented Dickey-Fuller (ADF) unit root test is calculated for the SOI and SST series. The results of the unit root tests are reported in Table 2, which indicate that both SOI and SST are stationary at the $1 \%$ significance level, so that the conditional volatility models can be used to capture time-varying volatility in the underlying data series.

\section{Empirical Results}

\subsection{AR(p) and ARMA(p,q) Processes}

In order to investigate ENSO volatility, a suitable time series model needs to be determined that satisfies appropriate regularity conditions. The first task is to determine the processes for the mean equation. From Tables 3, the ARMA $(1,1)$ process for the SOI series has the smallest Schwarz Bayesian Information Criterion (BIC), while ARMA $(3,2)$ has the smallest BIC for the SST series. The p-values of the Ljung-Box Q statistics of the residuals from the fitted models indicate that there is no autocorrelation at the 5\% level. The estimated $\operatorname{ARMA}(1,1)$ and $\operatorname{ARMA}(3,2)$ models are seen to be appropriate models for the SOI and SST series, respectively.

The specifications of the mean and variance equations for SOI and SST are given as follows:

$$
\begin{aligned}
& S O F A R M I A+) \varepsilon_{t} \\
& \text { conditional volatility }=\{\operatorname{GARCH}(1,1), \operatorname{GJR}(1,1) \text { or } \operatorname{EGARCH}(1,1)\}, \\
& S S T=A R M(B A, 2+) \varepsilon_{t} \\
& \text { conditional volatility }=\{\operatorname{GARCH}(1,1), \operatorname{GJR}(1,1) \text { or } \operatorname{EGARCH}(1,1)\} .
\end{aligned}
$$

\subsection{Alternative Volatility Models for SOI and SST}


The empirical estimates for alternative volatility models for the SOI and SST series are shown in Tables 4 and 5. The estimated model for the SOI and SST series for $\operatorname{GARCH}(1,1)$ shows that all the estimated coefficients satisfy the sufficient regularity conditions for the conditional variance to be positive $\left(h_{t} \geq 0\right)$. Moreover, the log-moment and second moment conditions are satisfied for SOI, so the QMLE for the two series are consistent and asymptotically normal. The estimates for the GJR(1,1) model show that SOI and SST satisfy the sufficient conditions for conditional volatility and the log-moment condition, which indicates that the QMLE of the parameters of the conditional volatility models for SOI and SST are consistent and asymptotically normal.

All the $\beta$ estimates from the $\operatorname{EGARCH}(1,1)$ model for SOI and SST are less than one in absolute value, which indicates that the estimates are likely to be consistent and asymptotically normal. As $\operatorname{EGARCH}(1,1)$ is a model of the logarithm of the conditional variance, there is no parametric restriction for conditional volatility to be positive. The size effects for the SOI and SST series have positive impacts on the conditional variance. These estimation results indicate that the sign effects have larger impacts than the size effects on the conditional variance. Furthermore, the appropriate model for the SOI series could be chosen by the BIC criterion and the regularity conditions. The GARCH $(1,1)$ model for the SOI and SST series is the optimal model as it has the smallest BIC value.

\subsection{Structural Change}

In order to examine whether structural change exists for the SOI series, the BP approach is implemented, and the estimates are shown in Table 6. The Table shows that the values of $\mathrm{UD}_{\max }$ and $\mathrm{WD}_{\max }$ are greater than the $5 \%$ critical value, which 
indicates the probable existence of structural breaks. As the values of $F(1 \mid 0), F(2 \mid 0)$, $F(3 \mid 0), F(4 \mid 0), F(5 \mid 0)$ exceed the critical value at the 5\% significance level, while the sequential $\operatorname{supF}(\mathrm{i}+1 \mid \mathrm{i})$ exhibits significance only for $\mathrm{i}=1$, this suggests there is only one break in the SOI series, which occurs at 1998(4).

The empirical results show there is a structural break for the SOI series in 1998. Based on either the SOI or SST index, the 1997-98 El Nino year was the strongest on record for any El Nino over the past 40 years. For instance, there were 14 El Nino years from 1950 to 1998 , based on the definition of ENSO using the SST index. The 3-month rolling means of the SST anomalies in the El Niño 3.4 region $\left(5^{\circ} \mathrm{N}-5^{\circ} \mathrm{S}\right.$, $\left.\left.120^{\circ}-170^{\circ} \mathrm{W}\right)\right]$ for $1997-98$ is 1.841 , is greater than for any other El Nino year. Such evidence explains why there is a structural break in 1998.

The strongest SST index in 1997-98 could be the result of global greenhouse gases emissions. For instance, Timmermann et al. (1999) have shown that global warming may cause the strength and frequency of ENSO events to change. In other words, the continuous growth of greenhouse gas emissions shifts the probability of strong El Nino and La Nina events. Such a relationship between ENSO strength and global greenhouse gas emissions will be examined later.

\subsection{Estimating the ENSO Volatility between two Different Structural Breaks}

This sub-section investigates and compares the ENSO volatility before and after the structural breakpoint. From the estimates of structural change, the breakpoint is located at April 1998, which will be treated as a boundary to split the sample into two periods for the SOI and SST series. In other words, the first period is from January 1950 to April 1998, while the second period is from May 1998 to July 2007. We have

estimated the $\operatorname{ARMA}(1,1)-\operatorname{GARCH}(1,1)$ model for SOI and the $\operatorname{ARMA}(3,2)-G A R C H(1,1)$ model for SST. 
The empirical results of volatility for SOI and SST are presented in Table 7. The $\operatorname{ARMA}(1,1)-\mathrm{GARCH}(1,1)$ estimates for SOI suggest that the short run persistence of shocks in periods 1 and 2 are 0.008 and 0.438 , respectively, while the long run persistence of shocks in periods 1 and 2 are 0.359 and 0.530 , respectively. The $\operatorname{ARMA}(3,2)-\operatorname{GARCH}(1,1)$ estimates for SST suggest that the short run persistence of shocks in periods 1 and 2 are 0.255 and 0.046 , respectively, while the long run persistence of shocks in periods 1 and 2 are 0.402 and 0.706, respectively. Both SOI and SST have larger long run persistence of shocks during the second period from May 1998. The estimates show that ENSO volatility has increased since 1998, which implies that the ENSO strength and frequency have increased recently. In other words, the ENSO strength using SOI and SST during the period 1998 to 2007 has increased by $47 \%$ and $75 \%$, respectively, which is consistent with the findings in Timmermann et al. (1999).

\section{The Strength of ENSO and Greenhouse Gas Emissions}

Greenhouse gas emissions increase as the economy grows, with carbon dioxide being the major greenhouse gas. Increasing carbon dioxide will lead to increasing greenhouse gases. The increasing concentrations of these greenhouse gases is called the greenhouse effect that will lead to global climate change as the average temperature of the Earth's surface increases (and hence global warming). Such an abnormal increase in temperatures is correlated with ENSO events. Based on this, we will analyze the relationship between the strength of ENSO and greenhouse gas emissions, and examine how these gases affect the frequency and strength of El Niño.

A quantitative definition of $\mathrm{El} \mathrm{Niño,} \mathrm{as} \mathrm{originally} \mathrm{proposed} \mathrm{by} \mathrm{the} \mathrm{Japan}$ Meteorological Agency (JMA), and subsequently modified by the Climate Variability and Predictability (CLIVAR) project, gives five-month rolling means of SST 
anomalies in the Nino 3.4 region $\left(5^{\circ} \mathrm{N}-5^{\circ} \mathrm{S}, 170^{\circ} \mathrm{W}-120^{\circ} \mathrm{W}\right)$ that exceed $0.4^{\circ} \mathrm{C}$ for six months or more, based on accepted concepts and designed to be consistent with previous recognized events. Conversely, La Niña occurs when this index is lower than $-0.4^{\circ} \mathrm{C}$ for at least six consecutive months. If the value of the index lies between $-0.4^{\circ} \mathrm{C}$ and $0.4^{\circ} \mathrm{C}$, it represents a normal state. Figure 1 represents a plot of SST from January 1950 to March 2005. From the right graph of Figure 1, we can easily distinguish which are the El Niño / La Niña years. For example, for the period 1982 to 1983, El Niño was in its warm phase, with the Sea Surface temperature above normal. From this plot, we observe that SST seems to have gained greater strength recently.

In order to analyze how greenhouse gases (especially for carbon dioxide) affect the strength and frequency of El Niño and La Niña, we analyze the SST and carbon dioxide emissions over the period 1950 to 2008 . Thus, in order to determine whether increasing greenhouse gas emissions will lead to a greater strength of El Niño/La Niña, we analyze the SST anomalies in the Nino 3.4 region's data base using the definition of El Niño and La Niña by JMA and CLIVAR. If the value for which the 12-month rolling means of SST anomalies in the Nino 3.4 region exceeds $0.4^{\circ} \mathrm{C}$ ( or lie below $-0.4^{\circ} \mathrm{C}$ ), the dependent variable is represented by the absolute value of the mean of the months which exceed $0.4^{\circ} \mathrm{C}$ or lie below $-0.4^{\circ} \mathrm{C}$. If the value for which the 12-month rolling means of SST anomalies in the Nino 3.4 region lies between $-0.4^{\circ} \mathrm{C}$ and $0.4^{\circ} \mathrm{C}$, the dependent variable is represented by 0.4 . Hence, we would have a large number of observations in our sample for which the SST anomalies are 0.4, which is an example of censored data.

The Tobit model is a regression model for censored distributions, which means there are no observations beyond a certain point. If there is a large proportion of observations at this censoring point, Ordinary Least Squares (OLS) techniques may 
lead to biased estimates. Based on this, we can specify the model as:

$$
\begin{array}{r}
y_{i}=\beta x_{i}+u_{i} \\
0.4
\end{array} \quad\left\{\begin{array}{c}
\text { if } y_{i}^{*} \geq 0.4 \text { or } y_{i}^{*} \leq-0.4 \\
\text { if }-0.4<y_{i}^{*}<0.4
\end{array}\right.
$$

where $y_{i}^{*}$ is the value for which the 12-month rolling means of SST anomalies lie in the Nino 3.4 region, $x_{i}$ is the carbon dioxide emission at time $i$, and $u_{i}$ is the error term which is assumed to be normally distributed with zero mean and variance $\sigma^{2}$.

The estimates from the Tobit regression are presented in Table 8. The estimated coefficient shows the expected signs that carbon dioxide emissions have a positive effect on the value of SST anomalies in the Nino 3.4 region. Thus, as carbon dioxide emissions increase, the value of SST anomalies in the Nino 3.4 region will be higher, which explains why the strength of El Niño or La Niña will increase as more greenhouse gases are emitted.

In order to forecast the strength of ENSO using future climate change, the estimates from Table 8 with future projections of Carbon Dioxide emissions are applied. Based on the IPCC (2007) report, global GHG emissions are projected to increase by 9.7 to $36.7 \mathrm{GtCO}_{2}$-eq (25\% to $90 \%$ ) between 2000 and 2030 , while $\mathrm{CO}_{2}$ emissions from energy use between 2000 and 2030 are projected to grow by $40 \%$ to $110 \%$ over the same period. Therefore, an increase of $40 \%$ to $110 \%$ of $\mathrm{CO}_{2}$ emissions is applied in this paper.

Maddala (1983) shows that the prediction equation for the Tobit model can be written as $\frac{\partial E(y)}{\partial x_{j}}=\Phi\left(\beta^{\prime} x / \sigma\right) \beta_{j}$, where $\sigma$ is the standard error of the estimated equation and $\Phi$ is the cumulate distribution function. The forecast of ENSO strength in 2030 will increase by $29.62 \%$ to $81.5 \%$ if global $\mathrm{CO}_{2}$ emissions increase by $40 \%$ to $110 \%$, respectively. 


\section{Concluding Remarks}

Three major contributions of this paper are as follows. The first finding is to determine an empirically adequate model of volatility of the Southern Oscillation by checking the regularity conditions of the estimated models, and then detecting whether structural breaks exist in the climate indexes. The GARCH, GJR and EGARCH models were estimated for the SOI and SST indexes, to answer the following questions: Under what conditions do GARCH-type processes have finite moments? Under what conditions are they stationary? These questions are important as the existence of moments permits verification of theoretical models to match stylized facts, such as fat tails and the temporal persistence observed in financial data (Carrasco and Chen, 2002), as well as economic and environmental data, including greenhouse gas emissions and carbon pollution data.

Although there have been many contributions to the ARCH/GARCH literature, it seems that until recently very little attention has been paid to appropriate model selection. Therefore, we conclude that nonlinear models are suitable for modelling the SOI and SST indexes after checking the regularity conditions.

In the second task, we tested for structural breaks in SOI and SST by using the Bai and Perron $(1998,2003)$ test, and then estimated the volatility of the SOI and SST indexes based on the structural breaks. The results showed that SOI had a structural break point in 1998(04). Therefore, we re-estimated the $\operatorname{ARMA}(1,1)-\operatorname{GARCH}(1,1)$ model for SOI and the $\operatorname{ARMA}(3,2)-\operatorname{GARCH}(1,1)$ for SST to examine volatility with 1998(04) as a structural change point.

The results indicated that the contribution of shocks to long run persistence of SOI and SST during 1998(05)-2007(07) was larger than during 1950(01)-1998(04), 
such that the volatility of ENSO over the decade had become stronger than during the previous 50 years. In other words, the ENSO strength has increased significantly since 1998. Such an increase in the ENSO strength may lead to greater damage worldwide. Chen et al. (2008) have shown that the additional welfare will lead to a loss in the global rice market by US\$595 million and US\$637 million if the strength of the El Nino and La Nina events, respectively, were to continue to increase unabated.

Finally, the linkage between ENSO strength and carbon dioxide was examined and a positive relationship was found. This implies that the strength of El Niño or La Niña will increase as more greenhouse gases are emitted. Such estimated outcomes with the future projections of carbon dioxide emissions are used to forecast the strength of ENSO under future climate change scenarios. We are able to predict that ENSO strength in 2030 will increase by $29.62 \%$ to $81.5 \%$ if global $\mathrm{CO}_{2}$ emissions increase by $40 \%$ to $110 \%$, respectively. This gives a very strong indication that we will faced with far stronger El Nino or La Nina effects in the future if global greenhouse gas emissions are not brought under greater control, especially as there is substantial scientific evidence that these gases affect the frequency and strength of the El Niño impact on the global economy. 


\section{References}

Adams, R.M., Chen, C.C., McCarl, B., Weiher, R., 1999. The economic consequences of ENSO events on agriculture, Climate Research, 13(3), 165-172.

Ahn, J.H., Kim, H.S., 2005. Nonlinear modeling of El Niño/Southern Oscillation index, Journal of Hydrologic Engineering, 10, 8-15.

Andrews, D.W.K., 1993. Tests for parameter instability and structural change with unknown change point, Econometrica, 61(4), 821-856.

Bai, J., Perron, P., 1998. Estimating and testing linear models with multiple structural changes, Econometrica, 66(1), 47-78.

Bai, J., Perron, P., 2003. Computation and analysis of multiple structural change models, Journal of Applied Econometrics, 18(1), 1-22.

Bollerslev, T., 1986. Generalized autoregressive conditional heteroscedasticity, Journal of Econometrics, 31, 307-327.

Brian, J., Berry, L., Qkulicz-Kozaryn, A., 2008. Are there ENSO signal in the macroeconomy?, Ecology Economics, 64(3), 625-633.

Brunner, A.D., 2002. El Niño and world primary commodity prices: warm water or hot air?, Review of Economics and Statistics, 84, 176-183.

Carrasco, M., Chen, X., 2002. Mixing and moment properties of various GARCH and stochastic volatility models, Econometric Theory, 18, 17-39.

Chen, C.C., McCarl, B., 2000. The value of ENSO information: Considerations of uncertainty and trade, Journal of Agricultural and Resource Economics, 25(2), 368-385.

Chen, C.C., McCarl, B., Adams, R., 2001. Economic implications of potential ENSO frequency and strength shifts, Climatic Change, 49, 147-159.

Chen, C.C., McCarl, B.A., Hill, H., 2002. An agricultural value of ENSO information under alternative phase definition, Climatic Change, 54, 305-325. 
Chen, C.C., Gillig, D., McCarl, B.A., Williams, L., 2005. ENSO impacts on regional water management: Case study of the Edwards Aquifer (Texas, USA), Climate Research, 28, 175-182.

Chu, P.S., Katz, R.W., 1985. Modeling and forecasting the Southern Oscillation: A time-domain approach, Monthly Weather Review, 113, 1876-1888.

Chow, G.C., 1960. Test of equality between sets of coefficients in two linear regressions, Econometrica, 28(3), 591-605.

Divino, J.A., McAleer, M., 2009. Modelling sustainable international tourism demand to the Brazilian Amazon, Environmental Modelling and Software, 1411-1419.

Davis, M., 2001. Late victorian holocausts: El Niño Famines and the Making of the Third World, Verso, London.

Debelle, G., Stevens, G., 1995. Monetary policy goals for inflation in Australia, Reserve Bank of Australia Research Discussion Paper No. 9503.

Dickey, D.A., Fuller, W.A., 1979. Distribution of the estimators for autoregressive time Series with a unit root, Journal of the American Statistical Association, 74, $427-431$

Dickey, D.A., Fuller, W.A., 1981. Likelihood ratio statistics for autoregressive time series with a unit root, Econometrica, 49, 1057-1072.

Dilley, M., 1997. Climatic factors affecting annual maize yields in the valley of Oaxaca, Mexico, International Journal of Climatology, 17, 1549-1557.

Dracup, J.A., Kahya, E., 1994. The relationships between U.S. streamflow and La Niña events, Water Resources Research, 30(7), 2133-2141.

Engle, R.F., 1982. Autoregressive conditional heteroskedasticity with estimates of the variance of United Kingdom inflation, Econometrica, 50, 987-1007.

Glosten, L., Jagannathan, R., Runkle, D., 1992. On the relation between the expected value and volatility of nominal excess return on stocks, Journal of Finance, 46, 
$1779-1801$

Handler, P., Handler, E., 1983. Climatic anomalies in the tropical Pacific ocean and corn yields in the United States, Science, 220, 1155-1156.

Hansen, B.E., 2001. The new econometrics of structural change: Dating breaks in U.S. labor productivity, Journal of Economic Perspectives, 15(4), 117-128.

Intergovernmental Panel on Climate Change IPCC, 2007: Climate Change 2007: Impacts, Adaptation and Vulnerability, Cambridge: Cambridge University Press.

Kovats, R.S., Bouma, M.J., Hajat, S., Worrall, E., Haines, A., 2003. El Niño and health, Lancet, 362, 1481-1489.

Ling, S., McAleer, M., 2002a. Stationarity and the existence of moments of a family of GARCH processes, Journal of Econometrics, 106, 109-117.

Ling, S., McAleer, M., 2002b. Necessary and sufficient moment conditions for the GARCH $(r, s)$ and asymmetric power GARCH $(r, s)$ models, Econometric Theory, $18,722-729$.

Ling, S., McAleer, M., 2003a. Asymptotic theory for a vector ARMA-GARCH model, Econometric Theory, 19, 278-308.

Ling, S., McAleer, M., 2003b. On adaptive estimation in nonstationary ARMA models with GARCH errors, Annals of Statistics, 31, 642-674.

Maddala, G.S., 1983. Limited-dependent and qualitative variables in Econometrics, Cambridge University Press.

McAleer, M., 2005. Automated inference and learning in modeling financial volatility, Econometric Theory, 21, 232-261.

McAleer, M., Chan, F., Marinova, D., 2007. An econometric analysis of asymmetric volatility: Theory and application to patents, Journal of Econometrics, 139, $259-284$

McBride, J.L., Nicholls, N., 1983. Seasonal relationships between Australian rainfall 
and the Southern Oscillation, Monthly Weather Review, 111, 1998-2004.

Moss, M.E., Pearson, C.P., McKerchar, A.I., 1994. The Southern Oscillation index as a predictor of the probability of low streamflows in New Zealand, Water Resources Research, 30(10), 2717-2723.

Naylor, R.L., Falcon, W.P., Rochberg, D., Wada, N., 2001. Using El Niño/Southern Oscillation climate data to predict rice production in Indonesia, Climate Change, $50,255-265$.

Nelson, D.B., 1990. Stationarity and persistence in the $\operatorname{GARCH}(1,1)$ model, Econometric Theory, 6, 318-334.

Nelson, D.B., 1991.Conditional heteroscedasticity in asset returns: A new approach, Econometrica, 59, 347-370.

Quandt, R.E., 1958. The estimation of parameters of a linear regression system obeying two separate regimes, Journal of the American Statistical Association, $53,873-880$.

Piechota, T.C., Dracup, J.A. 1996. Drought and regional hydrologic variation in the United States: Associations with the El Nino-Southern Oscillation, Water Resources Research, 32(5), 1359-1373.

Pielke, Jr. R.A., Landsea, C.W., 1999. La Niña, El Niño, and Atlantic hurricane damages in the United States, Bulletin of the American Meteorological Society, 80, 2027-2033.

Ropelewski, C.F., Halpert, M.S., 1989. Precipitation patter associated with the high index phase of the Southern Oscillation, Journal of Climate, 2(3), 268- 284.

Shephard, N., 1996. Statistical aspects of ARCH and stochastic volatility, in Time Series Models in Econometrics, Finance and Other Fields, Cox, D.R., Hinkley, D.V., Barndoff-Nielson, O.E. (eds.), London: Chapman and Hall, pp. 1-67.

Solow, A., Adams, R.F., Bryant, K.J., Legler, D., O’Brien, J., McCarl, B.A., Nayda, 
W., Weiher, R., 1998. The value of improved ENSO prediction to U.S. agriculture, Climatic Change, 39, 47-60.

Timmermann, A.J., Oberhuber, A., Bacher, M., Esch, M., Latif, Roeckner, E., 1999. Increased El Niño frequency in a climate model forced by future greenhouse warming, Nature, 398, 694-97.

Trenberth, K.E., 1997. The definition of El Niños, Bulletin of the American Meteorological Society, 78, 2771-2777.

Trenberth, K.E., Hoar, T.J., 1996. The 1990-1995 El Niños-Southern Oscillation event: Longest on Record, National Center for Atmospheric Research, Boulder, Colorado.

Wong, H., Li, W.K., 1997. On a multivariate conditional heteroscedastic model, Biometrika, 4, 111-123. 

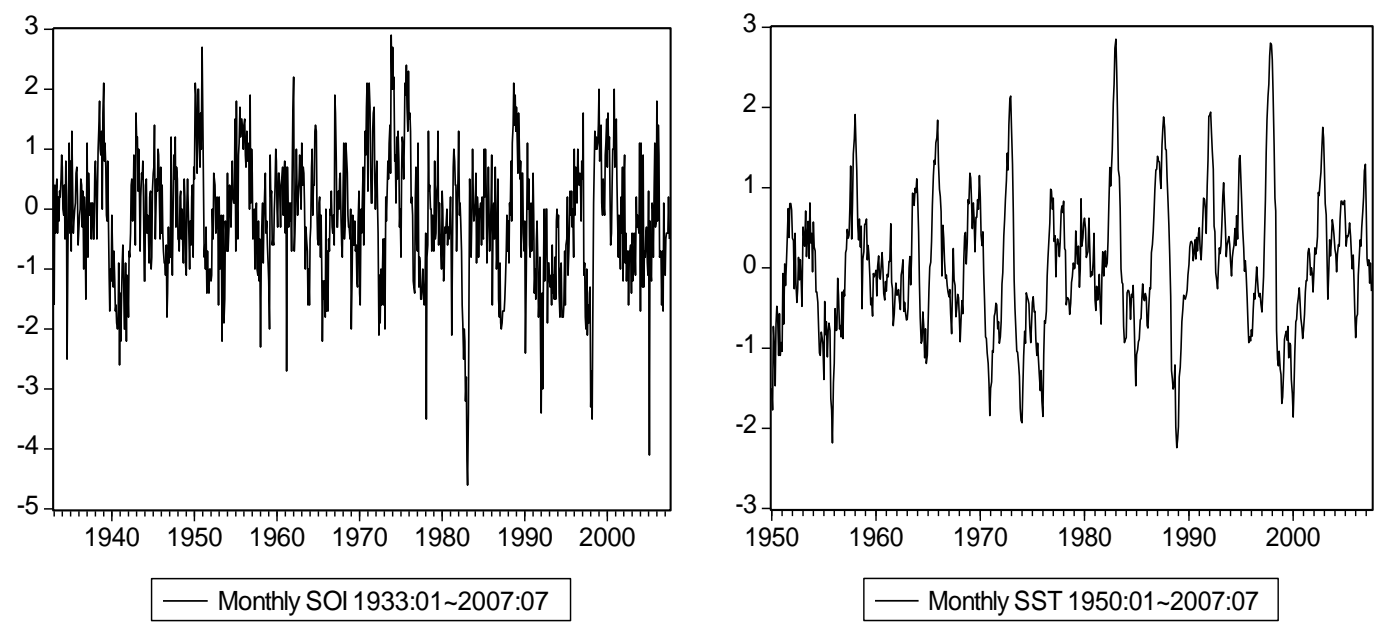

Figure 1. SOI and SST series 
Table 1

Descriptive Statistics for the SOI and SST Series

\begin{tabular}{|c|c|c|c|c|c|c|c|}
\hline Variables & $\begin{array}{c}\text { Number of } \\
\text { observations }\end{array}$ & Mean & Max & Min & Std Dev & $\mathrm{Q}(\mathrm{p})$ & JB \\
\hline SOI & 895 & -0.147 & 2.900 & -4.600 & 1.048 & $\begin{array}{c}1290.20 \\
(0.00)\end{array}$ & $\begin{array}{l}30.09 \\
(0.00)\end{array}$ \\
\hline SST & 691 & 0.018 & 2.85 & -2.250 & 0.859 & $\begin{array}{c}2149.50 \\
(0.00)\end{array}$ & $\begin{array}{l}19.09 \\
(0.00)\end{array}$ \\
\hline
\end{tabular}

Notes:

1. $\mathrm{Q}(\mathrm{p})$ is the Box-Pierce statistic of serial independence.

2. JB is the Jarque-Bera Lagrange multiplier test of normality.

3. Values in parentheses denote p-values. 
Table 2

ADF Unit Root Test for SOI and SST Series

\begin{tabular}{ccccccc}
\hline Variables & \multicolumn{2}{c}{ Level } & \multicolumn{3}{c}{ First-Difference Level } \\
& Model 1 & Model 2 & Model 3 & Model 1 & Model 2 & Model 3 \\
\hline SOI & $-8.17(12)^{*}$ & $-8.24(9)^{*}$ & $-8.06(9)^{*}$ & $-20.60(8)^{*}$ & $-20.59(10)^{*}$ & $-20.61(7)^{*}$ \\
SST & $-7.87(10)^{*}$ & $-7.90(10)^{*}$ & $-7.86(9)^{*}$ & $-15.76(9)^{*}$ & $-15.75(9)^{*}$ & $-15.77(8)^{*}$ \\
\hline
\end{tabular}

Notes:

$1: *$ represents significance at the $1 \%$ level.

2: Model 1:auxiliary regression equation with only intercept.

Model 2: auxiliary regression equation with only time trend.

Model 3: auxiliary regression equation with intercept and time trend.

3: BIC is the criterion for selecting the optimal lag length, and values in parentheses denote the lag length. 
Table 3

ARMA(p,q) Models for SOI and SST Series

\begin{tabular}{cccccc}
\hline & \multicolumn{2}{c}{ SOI } & & \multicolumn{2}{c}{ SST } \\
\hline $\mathrm{p}$ & $\mathrm{q}$ & $\mathrm{BIC}$ & $\mathrm{p}$ & $\mathrm{q}$ & $\mathrm{BIC}$ \\
\hline 1 & 0 & 2.481 & 1 & 0 & 0.573 \\
1 & 1 & 2.387 & 1 & 2 & 0.561 \\
2 & 0 & 2.405 & 2 & 1 & 0.530 \\
2 & 2 & 2.391 & 2 & 2 & 0.531 \\
3 & 0 & 2.392 & 3 & 1 & 0.524 \\
5 & 2 & 2.410 & 3 & 2 & 0.481 \\
5 & 4 & 2.412 & 3 & 3 & 0.490 \\
6 & 2 & 2.421 & 3 & 4 & 0.540 \\
6 & 3 & 2.416 & 4 & 1 & 0.527 \\
& & & 4 & 2 & 0.534 \\
& & & 4 & 3 & 0.538 \\
\hline
\end{tabular}


Table 4

ARMA $(1,1)$ and GARCH, GJR and EGARCH Models for SOI

\begin{tabular}{crrr}
\hline Variable(SOI) & \multicolumn{3}{c}{ Model } \\
\cline { 2 - 4 } & GARCH(1,1) & GJR $(1,1)$ & EGARCH(1,1) \\
\hline Mean Equation & & & \\
AR(1) & $0.896(0.021)$ & $0.901(0.019)$ & $0.896(0.019)$ \\
MA(1) & $-0.477(0.044)$ & $-0.474(0.042)$ & $-0.471(0.042)$ \\
Variance Equation & & & \\
$\omega$ & $0.337(0.145)$ & $0.470(0.166)$ & $-0.532(0.144)$ \\
$\alpha$ & $0.103(0.044)$ & $0.202(0.063)$ & $0.245(0.071)$ \\
$\beta$ & $0.361(0.152)$ & $0.127(0.267)$ & $0.077(0.043)$ \\
$\gamma$ & & $-0.139(0.072)$ & $0.292(0.261)$ \\
Log moment & -0.351 & -0.719 & \\
Second moment & 0.464 & 0.127 & 2.404 \\
BIC & 2.399 & 2.405 & \\
\hline
\end{tabular}


Table 5

ARMA $(3,2)$ and GARCH, GJR and EGARCH models for SST

\begin{tabular}{crrr}
\hline Variable(SST) & \multicolumn{3}{c}{ Model } \\
\cline { 2 - 4 } Mean Equation & GARCH(1,1) & GJR $(1,1)$ & EGARCH $(1,1)$ \\
AR(1) & $0.823(0.045)$ & $0.849(0.032)$ & $0.858(0.029)$ \\
AR(2) & $0.957(0.006)$ & $0.955(0.006)$ & $0.958(0.005)$ \\
AR(3) & $-0.846(0.041)$ & $-0.866(0.029)$ & $-0.876(0.026)$ \\
MA(1) & $0.233(0.060)$ & $0.188(0.048)$ & $0.179(0.044)$ \\
MA(2) & $-0.762(0.059)$ & $-0.807(0.048)$ & $-0.816(0.044)$ \\
Variance Equation & & & \\
$\omega$ & $0.003(0.045)$ & $0.051(0.051)$ & $-1.667(0.450)$ \\
$\beta$ & $0.034(0.006)$ & $0.179(0.092)$ & $0.400(0.095)$ \\
$\gamma$ & $0.930(0.059)$ & $0.224(0.110)$ & $0.447(0.053)$ \\
Log moment & & $0.125(0.177)$ & $-0.067(0.176)$ \\
Second moment & -0.015 & -0.712 & \\
BIC & 0.963 & 0.466 & 0.485 \\
\hline
\end{tabular}

Note: Values in parentheses denote standard errors. 
Table 6

Results of SOI for Structural Break Tests

\begin{tabular}{|c|c|c|c|c|}
\hline Test & Hypothesis & & Statistics & \\
\hline & & & SOI & Critical value $^{\mathrm{a}}$ \\
\hline $\mathrm{UD}_{\max }$ & $\mathrm{H}_{0}: \mathrm{m}=0$ & $\mathrm{H}_{1: \mathrm{m}}>0$ & $13.14^{*}$ & 8.88 \\
\hline $\mathrm{WD}_{\max }$ & $\mathrm{H}_{0}: \mathrm{m}=0$ & $\mathrm{H}_{1: \mathrm{m}}>0$ & $13.14^{*}$ & 9.91 \\
\hline \multirow[t]{5}{*}{ supF(i|0) Test } & $\mathrm{H}_{0}: \mathrm{m}=0$ & $\mathrm{H}_{1: \mathrm{m}}=1$ & $13.14^{*}$ & 8.58 \\
\hline & $\mathrm{H}_{0}: \mathrm{m}=0$ & $\mathrm{H}_{1: \mathrm{m}}=2$ & $8.04^{*}$ & 7.22 \\
\hline & $\mathrm{H}_{0}: \mathrm{m}=0$ & $\mathrm{H}_{1: \mathrm{m}}=3$ & $7.37^{*}$ & 5.96 \\
\hline & $\mathrm{H}_{0}: \mathrm{m}=0$ & $\mathrm{H}_{1: \mathrm{m}}=4$ & $5.58^{*}$ & 4.99 \\
\hline & $\mathrm{H}_{0}: \mathrm{m}=0$ & $\mathrm{H}_{1: \mathrm{m}}=5$ & $4.50^{*}$ & 3.91 \\
\hline \multirow[t]{4}{*}{$\operatorname{supF}(i+1 \mid i)$ Test } & $\operatorname{supF}(2 \mid 1)$ & & $7.34^{*}$ & 8.58 \\
\hline & $\operatorname{supF}(3 \mid 2)$ & & 2.49 & 10.13 \\
\hline & $\operatorname{supF(4|3)}$ & & 2.02 & 11.14 \\
\hline & $\operatorname{supF}(5 \mid 4)$ & & 0.00 & 11.83 \\
\hline \multirow[t]{4}{*}{ LWZ } & 1 & $0.1662^{*}$ & & \\
\hline & 2 & 0.1889 & & \\
\hline & 3 & 0.2228 & & \\
\hline & 4 & 0.2581 & & \\
\hline
\end{tabular}

Notes:

"a" is the critical value at 5\%, while "*" represents significance at 5\%.

LWZ(1): denotes the number of breaks chosen by LWZ to be 1 . 
Table 7

Estimates of ENSO Volatility for Different Periods

\begin{tabular}{|c|c|c|c|c|}
\hline & \multicolumn{2}{|c|}{ SOI } & \multicolumn{2}{|c|}{ SST } \\
\hline & Period 1 & Period 2 & Period 1 & Period 2 \\
\hline \multicolumn{5}{|c|}{ Mean Equation } \\
\hline \multirow[t]{2}{*}{$\operatorname{AR}(1)$} & 0.905 & 0.869 & 0.890 & 0.287 \\
\hline & $(0.024)$ & $(0.044)$ & $(0.023)$ & $(0.245)$ \\
\hline \multirow[t]{2}{*}{$\operatorname{AR}(2)$} & & & 0.960 & 0.709 \\
\hline & & & $(0.010)$ & $(0.111)$ \\
\hline \multirow[t]{2}{*}{$\operatorname{AR}(3)$} & & & -0.899 & -0.168 \\
\hline & & & $(0.021)$ & $(0.196)$ \\
\hline \multirow[t]{2}{*}{ MA(1) } & -0.453 & -0.439 & 0.112 & 1.015 \\
\hline & $(0.051)$ & $(0.141)$ & $(0.033)$ & $(0.255)$ \\
\hline \multirow[t]{2}{*}{$\operatorname{MA}(2)$} & & & -0.880 & 0.177 \\
\hline & & & $(0.036)$ & $(0.231)$ \\
\hline \multicolumn{5}{|c|}{ Variance Equation } \\
\hline \multirow[t]{2}{*}{$\omega$} & 0.363 & 0.413 & 0.058 & 0.015 \\
\hline & $(0.243)$ & $(0.236)$ & $(0.017)$ & $(0.015)$ \\
\hline \multirow[t]{2}{*}{$\alpha$} & 0.008 & 0.438 & 0.255 & 0.046 \\
\hline & $(0.053)$ & $(0.210)$ & $(0.077)$ & $(0.012)$ \\
\hline \multirow[t]{2}{*}{$\beta$} & 0.351 & 0.092 & 0.147 & 0.660 \\
\hline & $(0.408)$ & $(0.279)$ & $(0.190)$ & $(0.316)$ \\
\hline
\end{tabular}

Note: Values in parentheses denote standard errors 
Table 8

Tobit Regression Results

Tobit Analysis, Limit $=0.4$

\begin{tabular}{llll}
\hline Variable & $\begin{array}{l}\text { Coefficient } \\
\text { Estimate }\end{array}$ & $\begin{array}{l}\text { Standard } \\
\text { Error }\end{array}$ & t-Ratio \\
\hline CO2 & 0.0001426 & 0.00003819 & 3.734 \\
\hline Log Likelihood & -54.998 & & \\
Limit Observation & 26 & & \\
Non-Limit Observation & 33 & & \\
\hline
\end{tabular}

Note: Carbon dioxide emissions are measured in millions of tons. 